LETTER TO JMG

\title{
Protective and susceptibility effects of hSKCa3 allelic variants on juvenile myoclonic epilepsy
}

\author{
J Vijai, A Kapoor, H M Ravishankar, P J Cherian, G Kuruttukulam, B Rajendran, R Sridharan, \\ G Rangan, A S Girija, S Jayalakshmi, S Mohandas, K S Mani*, K Radhakrishnan, A Anand
}

Jatis uvenile myoclonic epilepsy (JME; OMIM 606904) is a subtype of common idiopathic generalised epilepsy (IGE) and affects up to $26 \%$ of all individuals with IGE. ${ }^{1-3} \mathrm{JME}$ is characterised by the onset in adolescence of bilateral myoclonic jerks usually affecting the upper limbs. ${ }^{14}$ Patients also have generalised tonic-clonic seizures and about one third experience absence seizures. Genetic factors are known to play an important role in the etiology of JME. ${ }^{3}$ While identification of genes underlying predisposition to JME has been relatively slow due to clinical and genetic heterogeneity, ${ }^{56}$ progress made so far in the isolation and characterisation of genes associated with other monogenic subtypes of IGE, provides evidence that most idiopathic epilepsy syndromes are caused by mutations in genes encoding ion channels. ${ }^{7}$ The implications of these findings in monogenic subtypes of the disorder for the complex polygenic subset are now being increasingly appreciated. ${ }^{8}$

Two types of voltage gated potassium channels have been associated with seizure disorders, the KCNQ channels and the $\mathrm{K}_{\mathrm{V}}$ channels. Loss of function mutations for the potassium channels $K C N Q 2$ and $K C N Q 3$ have been identified in families with a rare autosomal dominant subtype of IGE called benign familial neonatal convulsions (BFNC). ${ }^{10}$ Allelic association of JME with KCNQ3 has been suggested in a South Indian cohort of JME patients. ${ }^{11}$ Mutation in human KCNIA predisposes to episodic ataxia and partial epilepsy. ${ }^{12}$ These findings emphasise the importance of potassium channels in controlling neuronal excitability and thus make potassium channel genes potentially interesting candidates for idiopathic epilepsy syndromes.

The calcium activated potassium channels are an interesting class of potassium channels that regulate neuronal excitability. ${ }^{13}{ }^{14}$ These are gated by intracellular calcium ions and their activity is responsible in part for the afterpolarisation that follows a single action potential or a train of action potentials in the neurons. According to their single channel conductance in symmetrical potassium solutions, these channels are classified ${ }^{13}{ }^{14}$ as big (BK), intermediate (IK), or small (SK). Biophysical and pharmacological analysis, single cell mRNA, and protein expression profiling strongly suggest that SK3 channels mediate the calcium dependent afterhyperpolarisation in neurons. ${ }^{15}$ The neuronal small conductance calcium activated potassium channel ( $h \mathrm{SKCa} 3$ ) plays a critical role in determining the firing pattern of neurons through the generation of slow afterhyperpolarisation ${ }^{16}{ }^{17}$ and regulation of intracellular calcium signals by binding with calmodulin. ${ }^{18}$ In situ hybridisation in rat $^{19}$ and human brain ${ }^{20}$ revealed that mRNAs encoding the SK family subunits are widely expressed in the brain and show distinct but overlapping patterns. These physiological attributes make hSKCa3 an interesting candidate gene for investigation in an IGE syndrome such as JME. While its role in schizophrenia and bipolar disorders has been investigated, ${ }^{16}{ }^{20-23}$ the

\section{Key points}

- Genetic factors are known to play an important role in the etiology of juvenile myoclonic epilepsy (JME), a subtype of common idiopathic generalised epilepsy.

- Most idiopathic epilepsy syndromes are caused by mutations in genes encoding ion channels.

- The length variation in the second polyglutamine stretch of the neuronal small conductance calcium activated potassium channel gene hSKCa3 was investigated and the allele frequency distribution was compared between 222 well characterised JME patients of South Indian origin and 248 ethnically matched normal subjects.

- Alleles $C A G_{16}$ and $C A G_{18}$ were common while $C A G_{19}$ was rare in the studied JME patients with relative risks of $1.198,1.178$, and 0.514 , respectively.

possibility of its influence on epilepsy phenotypes remains poorly studied.

hSKC $a 3^{16}$ encodes a 731 amino acid protein comprising two polyglutamine arrays in its $\mathrm{N}$ terminus of which the second polyglutamine repeat is highly polymorphic. ${ }^{16}$ We investigated the length variation in the second polyglutamine stretch of $h \mathrm{SKCa}_{3}$ and compared the allele frequency distribution between 222 well characterised JME patients of South Indian origin ${ }^{24}$ and 248 ethnically matched normal subjects. Several genetic studies have been conducted on the South Indian populations and it has been found that the genetic distance between even the tribal populations is small, signifying a close genetic relationship. ${ }^{25}$ Through this casecontrol design, we intended to investigate whether variations in the length of the expressed polyglutamine tract of $h S K C a 3$ show allelic association with JME and thereby possibly influence expression of the JME phenotype.

\section{METHODS}

\section{Patients and controls}

A total of 222 unrelated JME probands were recruited through epilepsy centres situated in South India. ${ }^{24}$ Patient samples were collected from specialty neurology clinics, referral centres, and medical camps for seizure disorders which were part of the rural outreach programs of the referral centres. All the patients were unambiguously diagnosed cases of JME with classification based on the published criteria of the Commission on Classification and Terminology of the

Abbreviations: BFNC, benign familial neonatal convulsions; HWE, Hardy-Weinberg equilibrium; IGE, idiopathic generalised epilepsy; $J M E$, juvenile myoclonic epilepsy; PCR, polymerase chain reaction 


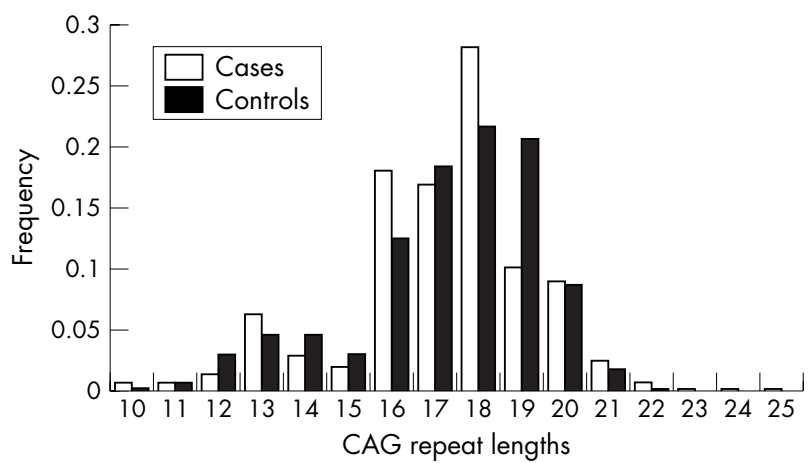

Figure 1 hSKCa3 allele frequencies in cases and controls.

International League Against Epilepsy. ${ }^{2}$ A total of 248 subjects of South Indian origin without a family history of epilepsy, ataxia, unexplained blackouts, or other chronic neurological disorders were used as controls in this study. All patients and controls provided written informed consent and the study was approved by Institutional Bioethics Review Board.

\section{Genetic analysis}

Genomic DNA was isolated from peripheral venous blood by phenol-chloroform method. Polymerase chain reaction (PCR) mediated amplification of the second polyglutamine CAG tract of $h S K C a 3$ was carried out in all subjects. Each reaction comprised of $50 \mathrm{ng}$ of genomic DNA, 20 pmol primers (hSKCa3-F: 5'-CAC CGT CAG TGT CAC CAG TAG TCC CC$3^{\prime}$ and hSKCa3-R: 5'-Hex-GAA GGG GTT GCT GTC CCG CCG GT-3'), ${ }^{16} 200 \mu \mathrm{M}$ of each dNTP, $50 \mathrm{mM} \mathrm{KCl}, 10 \mathrm{mM}$ Tris- $\mathrm{HCl}$ (pH 8.3), $1.5 \mathrm{mM} \mathrm{MgCl}_{2}$, and $0.5 \mathrm{U}$ Taq DNA polymerase in $10 \mu \mathrm{l}$ final volume. Forty cycles of PCR were carried out, each cycle with denaturation at $94^{\circ} \mathrm{C}$ for $40 \mathrm{~s}$, annealing at $52^{\circ} \mathrm{C}$ for $40 \mathrm{~s}$, and extension at $72^{\circ} \mathrm{C}$ for $45 \mathrm{s.}^{23}$ Genotyping was performed by a person unaware of the affection status using an ABI 3100 Genetic Analyzer (Applied Biosystems, Foster City, CA). Allele sizing was done using Genotyper version 2.0 (Applied Biosystems).

\section{Statistical analysis}

Descriptive statistics were calculated for patient and control data. Statistical tests were done as follows. Z tests of proportions were computed in controls and cases in order to obtain information on each individual allele. Relative risks of the major alleles were calculated by computing the ratio of presence and absence of each allele in the cases and controls. Hardy-Weinberg equilibrium (HWE) was calculated in this study to test for genotype frequencies, especially in the control population as a measure to check for population stratification or genotyping errors.

\section{RESULTS}

The mean (SD) age at onset of the JME probands was 14.9 (1.4) years. The triad of myoclonus, absences, and generalised tonic-clonic seizures was observed in $27.9 \%$, the combination of myoclonus and generalised tonic-clonic seizures in $64.7 \%$, and myoclonus alone in $7.4 \%$ of patients. Of the patients $84 \%$ were receiving treatment with sodium valproate. Scalp electroencephalogram (EEG) during wakefulness and sleep exhibited generalised epileptiform abnormalities in about $70 \%$ of the patients, while $30 \%$ were seizure free for 2 or more years and therefore exhibited normal EEG. Clinical details of a large subset of these patients were recently reported. ${ }^{24}$

Sixteen distinct $h S K C a 3$ alleles were observed. Repeat size ranged from 10 to 25 . Thirteen alleles $\left(\mathrm{CAG}_{10-22}\right)$ were seen in the controls and 16 alleles $\left(\mathrm{CAG}_{10-25}\right)$ were seen in the patients. The frequency distribution of the observed alleles in cases and controls is shown in fig 1 . The modal repeat size was $\mathrm{CAG}_{18}$. Statistical tests for alleles with a frequency $>0.02$ were carried out to find out if one or more of these allelic variants showed significant frequency differences between the control and the patient group. $\mathrm{Z}$ test of proportions for the 10 alleles (alleles with frequency less than 0.02 were aggregated) was performed. In this analysis, the three alleles $\mathrm{CAG}_{16}$ (0.018), $\mathrm{CAG}_{18}(0.019)$, and $\mathrm{CAG}_{19}(<0.00001)$ were found to be significant. The distribution of $\mathrm{CAG}_{16}$ and $\mathrm{CAG}_{18}$ was higher in JME patients, while allele $\mathrm{CAG}_{19}$ was quite rare in JME cases but present at a very high frequency in the control group (table 1). When Bonferroni correction for multiple testing ( $\alpha$ at 0.005 ) was applied, only $\mathrm{CAG}_{19}$ was found to be significant. Among the nine major alleles $\left(\mathrm{CAG}_{13-21}\right)$ observed, relative risk was found to be maximum for allele $\mathrm{CAG}_{16}(1.198)$ and minimum for allele $\mathrm{CAG}_{19}$ (0.574) (table 2). We found the control population to be in HWE at the $5 \%$ significance level $\left(\chi^{2}=0.0154, p=0.9012\right.$, $\mathrm{df}=1$ ), while the cases deviated from HWE at the 5\% significance level $\left(\chi^{2}=5.5049, p=0.0189, \mathrm{df}=1\right)$.

\section{DISCUSSION}

Genetic association studies are one of the useful approaches to understanding the etiology of complex disorders. ${ }^{26}$ Increased or decreased allele or genotype frequencies in cases or controls implicate sequence variants that either increase or decrease the risk of a disease or are in strong linkage disequilibrium with a disease causing mutation. The biological effects of a specific risk or protective allele under study are usually small.

We tested the association of JME with allelic variants at an expressed polymorphic CAG repeat tract in a functionally important calcium activated potassium channel gene

Table 1 Allele frequencies and pair-wise $Z$ tests of JME cases and controls

\begin{tabular}{|c|c|c|c|c|c|c|}
\hline $\mathrm{CAG}_{\mathrm{n}}$ & Cases & Controls & p (cases) & $\mathrm{p}$ (controls) & $Z$ value & p Value \\
\hline 13 & 28 & 23 & 0.063 & 0.046 & 1.128 & 0.259 \\
\hline 14 & 13 & 23 & 0.029 & 0.046 & -1.36316 & 0.1728 \\
\hline 15 & 9 & 15 & 0.020 & 0.030 & -0.967 & 0.333 \\
\hline 16 & 80 & 62 & 0.180 & 0.125 & 2.358 & 0.018 \\
\hline 17 & 75 & 91 & 0.169 & 0.183 & -0.583 & 0.559 \\
\hline 18 & 125 & 107 & 0.282 & 0.216 & 2.336 & 0.019 \\
\hline 19 & 45 & 102 & 0.101 & 0.206 & -4.395 & $<0.00001$ \\
\hline 20 & 40 & 43 & 0.090 & 0.087 & 0.1832 & 0.855 \\
\hline 21 & 11 & 9 & 0.025 & 0.018 & 0.703 & 0.4819 \\
\hline $\mathrm{Agg}^{*}$ & 18 & 21 & 0.041 & 0.042 & -0.138 & 0.8902 \\
\hline
\end{tabular}

$\mathrm{CAG}_{n}$, number of CAG repeats in the polymorphic marker alleles observed; $\mathrm{p}$ (case), frequency in cases; $\mathrm{p}$ (control), frequency in controls. Agg*, aggregate of alleles with frequency less than 0.02 . 
Table 2 hSKCa3 allele-wise relative risk

\begin{tabular}{ll}
\hline Allele & Relative risk $^{*}$ \\
\hline 13 & 1.047 \\
14 & 0.705 \\
15 & 0.739 \\
16 & 1.198 \\
17 & 0.854 \\
18 & 1.178 \\
19 & 0.514 \\
20 & 0.956 \\
21 & 1.105 \\
\hline
\end{tabular}

*ff $R 1: A /(A+B), R 2: C /(C+D)$, then $R 1 / R 2$ is the relative risk of the allele where $A$ is alleles present in cases, $B$ is alleles present in controls, $C$ is alleles not present in cases, and $D$ is alleles not present in controls.

(hSKCa3). The allele $\mathrm{CAG}_{19}$ was found to be present at significantly different frequencies in cases and controls, implying its association with the JME phenotype. A previous report from a German population investigated 126 IGE patients (78 JME and 48 childhood absence epilepsy or juvenile absence epilepsy cases) and found no evidence for association between IGEs and hSKCa3. ${ }^{27}$ No evidence for association between IGEs and $h S K C a 3$ was found in this study. We have obtained results which are different from this published work. These differences are perhaps due to the use of different ethnic populations, different sample sizes, or differences in the subtypes of the clinical samples that were studied. The sample size used in our study was comparatively large and homogeneous and consisted only of JME cases of South Indian origin and a control sample from the same population. We found significant differences in the distribution of allele $\mathrm{CAG}_{16}, \mathrm{CAG}_{18}$, and $\mathrm{CAG}_{19}$ among South Indian JME probands and ethnically matched control subjects. These three alleles were significant without Bonferroni correction. When this correction was applied, $\mathrm{CAG}_{19}$ was the only allele found to be significant. However, we are concerned about the astuteness of the Bonferroni correction in this scenario as there is no logic in an a prior universal null hypothesis for all the alleles tested or in the study populations being identical on all the alleles analysed. This point has been addressed by Perneger. ${ }^{28}$ Bonferroni adjustments imply that a given comparison will be interpreted differently according to how many other tests were performed.

$\mathrm{CAG}_{16}$ and $\mathrm{CAG}_{18}$ were common while $\mathrm{CAG}_{19}$ was rare in the JME patients studied. The relative risks due to $\mathrm{CAG}_{16}$, $\mathrm{CAG}_{18}$, and $\mathrm{CAG}_{19}$ were found to be 1.198, 1.178, and 0.514, respectively. The most probable role of $\mathrm{CAG}_{16}, \mathrm{CAG}_{18}$, and $\mathrm{CAG}_{19}$ hSKCa3 variants may be in modulating the channel function. Alternatively, the role of $h \mathrm{SKCa} 3$ may not be simply as a numerical CAG counter. The possibility of additional sequences within $h S K C a 3$ that may influence the disease phenotype cannot be ruled out. Additional polymorphisms in the coding or regulatory regions of this complex gene that spans about $163 \mathrm{~kb}$ and has a complex promoter with binding sites for over 10 transcription factors may be involved. ${ }^{29}$

Dynamic CAG repeat expansions have been implicated in many neurological diseases. We did not observe a major expansion in the CAG repeat polymorphism in the probands studied. However, at least in two reported scenarios, CAG repeat length polymorphisms within the normal reported range have resulted in a disease state. These are Kennedy's disease $^{30}$ and spinocerebellar ataxia type $6 .^{31}$

We found observation of a possible protective effect on the JME phenotype interesting. Protective alleles are important modifiers of the phenotype. Unlike the alleles of susceptibility genes that are over-represented in affected individuals (cases) versus unaffected individuals (controls), protective alleles occur preferentially in healthy individuals, implying that their presence prevents disease despite the presence of other disease promoting (susceptibility) alleles at the same gene or genes elsewhere in the genome. Several reports have highlighted the importance of protective alleles in various disease conditions: deletion of CCR5 protects from HIV infection, 32 while HLA-DRB1l and HLA-DRQ03032 alleles are both over-represented in controls versus breast cancer ${ }^{33}$ cases. In the light of these findings, our results on the hSKCa3 alleles suggest it should be carefully analysed further in JME families.

\section{ACKNOWLEDGEMENTS}

We thank all patients and participants in this study. We thank Professor NV Joshi and Dr Renuka Nair for helpful criticism of the manuscript.

\section{Authors' affiliations}

J Vijai, P J Cherian, K Radhakrishnan, Department of Neurology, Sree Chitra Tirunal Institute for Medical Sciences and Technology,

Trivandrum, India

A Kapoor, H M Ravishankar, A Anand, Molecular Biology and Genetics Unit, Jawaharlal Nehru Centre for Advanced Scientific Research,

Bangalore, India

G Kuruttukulam, Lourdes Hospital, Cochin, India

B Rajendran, West Side Hospital, Cochin, India

R Sridharan, Apollo Hospital, Chennai, India

G Rangan, Sri Satya Sai Hospital, Bangalore, India

A S Girija, Department of Neurology, Medical College, Calicut, India

S Jayalakshmi, S Mohandas, Department of Neurology, Nizam's

Institute of Medical Sciences, Hyderabad, India

K S Mani, Neurological Clinic, Bangalore, India

The Sree Chitra Tirunal Institute Fellowship and grant CSIR-SRF to J Vijai are acknowledged. This study was supported by the DBT, New Delhi and JNCASR, Bangalore.

Competing interests: none declared

*Since deceased.

Correspondence to: Dr Anuranjan Anand, Molecular Biology and Genetics Unit, Jawaharlal Nehru Centre for Advanced Scientific Research, Bangalore 560 064, India; anand@jncasr.ac.in

Received 12 June 2004

Revised version received 19 October 2004

\section{REFERENCES}

1 Delgado-Escueta AV, Enrile-Bacsal F. Juvenile myoclonic epilepsy of Janz. Neurology 1984;34(3):285-94

2 Proposal for revised classification of epilepsies and epileptic syndromes. Commission on Classification and Terminology of the International League Against Epilepsy. Epilepsia 1989;30(4):389-99.

3 Grunewald RA, Panayiotopoulos CP. Juvenile myoclonic epilepsy. A review. Arch Neurol 1993;50(6):594-8.

4 Janz D. Epilepsy with impulsive petit mal (juvenile myoclonic epilepsy). Acta Neurol Scand 1985;72(5):449-59.

5 Greenberg DA, Delgado-Escueta AV. The chromosome 6p epilepsy locus: exploring mode of inheritance and heterogeneity through linkage analysis. Epilepsia 1993;34(Suppl 3):S12-8.

6 Greenberg DA, Durner M, Keddache M, Shinnar S, Resor SR, Moshe SL Rosenbaum D, Cohen J, Harden C, Kang H, Wallace S, Luciano D, BallabanGil K, Tomasini L, Zhou G, Klotz I, Dicker E. Reproducibility and complications in gene searches: linkage on chromosome 6, heterogeneity, association, and maternal inheritance in juvenile myoclonic epilepsy. Am J Hum Genet 2000:66(2):508-16

7 Mulley JC, Scheffer IE, Petrou S, Berkovic SF. Channelopathies as a genetic cause of epilepsy. Curr Opin Neurol 2003;16(2):171-6.

8 Gargus JJ. Unraveling monogenic channelopathies and their implications for complex polygenic disease. Am J Hum Genet 2003;72(4):785-803.

9 Singh NA, Westenskow P, Charlier C, Pappas C, Leslie J, Dillon J, Anderson VE, Sanguinetti MC, Leppert MF; BFNC Physician Consortium. $K C N Q 2$ and $K C N Q 3$ potassium channel genes in benign familial neonata convulsions: expansion of the functional and mutation spectrum. Brain 2003;126(Pt 12):2726-37.

10 Rogawski MA. KCNQ2/, KCNQ3 K+ channels and the molecular pathogenesis of epilepsy: implications for therapy. Trends Neurosci 2000;23(9):393-8. 
11 Vijai J, Kapoor A, Ravishankar HM, Cherian PJ, Girija AS, Rajendran B, Rangan G, Jayalakshmi S, Mohandas S, Radhakrishnan K, Anand A. Genetic association analysis of KCNQ3 and juvenile myoclonic epilepsy in a South Indian population. Hum Genet 2003;113(5):461-3

12 Browne DL, Gancher ST, Nutt JG, Brunt ER, Smith EA, Kramer P, Litt M. Episodic ataxia/myokymia syndrome is associated with point mutations in the human potassium channel gene, KCNA1. Nat Genet 1994;8(2):136-40.

13 Bond CT, Maylie J, Adelman JP. Small-conductance calcium-activated potassium channels. Ann N Y Acad Sci 1999:868:370-8.

14 Faber ES, Sah, P. Calcium-activated potassium channels: multiple contributions to neuronal function. Neuroscientist 2003;9(3):181-94.

15 Wolfart J, Neuhoff H, Franz O, Roeper J. Differential expression of the smallconductance, calcium-activated potassium channel SK3 is critical for pacemaker control in dopaminergic midbrain neurons. J Neurosci 2001;21(10):3443-56.

16 Chandy KG, Fantino E, Wittekindt O, Kalman K, Tong L-L, Ho T-H Gutman GA, Crocq M-A, Ganguli R, Nimgaonkar V, Morris-Rosendahl DJ, Gargus JJ. Isolation of a novel potassium channel gene hSKCa3 containing a polymorphic CAG repeat: a candidate for schizophrenia and bipolar disorder? Mol Psychiatry 1998;3(1):32-7.

17 Roncarati R, Di Chio M, Sava A, Terstappen GC, Fumagalli G. Presynaptic localization of the small conductance calcium-activated potassium channel SK3 at the neuromuscular junction. Neuroscience $2001 ; 104(1): 253-62$

18 Fanger CM, Ghanshani S, Logsdon NJ, Raver H, Kalman K, Zhou J Beckingham K, Chandy KG, Cahalan MD, Aiyar J. Calmodulin mediates calcium-dependent activation of the intermediate conductance KCa channel, IKCal. J Biol Chem 1999;274(9):5746-54.

19 Tacconi S, Carletti R, Bunnemann B, Plumpton C, Merlo PE, Terstappen GC. Distribution of the messenger RNA for the small conductance calciumactivated potassium channel SK3 in the adult rat brain and correlation with immunoreactivity. Neuroscience 2001;102(1):209-15.

20 Dror V, Shamir E, Ghanshani S, Kimhi R, Swartz M, Barak Y, Weizman R, Avivi L, Litmanovitch T, Fantino E, Kalman K, Jones EG, Chandy KG, Gargus JJ, Gutman GA, Navon R. hKCa3/KCNN3 potassium channel gene: association of longer CAG repeats with schizophrenia in Israeli Ashkenazi Jews, expression in human tissues and localization to chromosome 1q21. Mol Psychiatry 1999;4(3):254-60.

21 Miller MJ, Raver H, Tomita H, Raver H, Gargus JJ, Gutman GA, Cahalan MD Chandy KG. Nuclear localization and dominant-negative suppression by a mutant SKCa3 $\mathrm{N}$-terminal channel fragment identified in a patient with schizophrenia. J Biol Chem 2001;276(30):27753-6.

22 Antonarakis SE, Blouin JL, Lasseter VK, Gehrig C, Radhakrishna U, Nestadt G, Housman DE, Kazazian HH, Kalman K, Gutman G, Fantino E, Chandy KG,
Gargus JJ, Pulver AE. Lack of linkage or association between schizophrenia and the polymorphic trinucleotide repeat within the KCNN3 gene on chromosome 1q21. Am J Med Genet 1999;88(4):348-51.

23 Saleem Q, Sreevidya VS, Sudhir J, Vijaya Savithri J, Gowda Y, Rao CB, Benegal V, Majumber PP, Anand A, Brahmachari SK, Jain S. Association analysis of CAG repeats at the KCNN3 locus in Indian patients with bipolar disorder and schizophrenia. Am J Med Genet 2000;96(6):744-8.

24 Vijai J, Cherian PJ, Stlaja PN, Anand A, Radhakrishnan K. Clinical characteristics of a South Indian cohort of juvenile myoclonic epilepsy probands. Seizure 2003;12(7):490-6.

25 Vishwanathan H, Deepa E, Cordaux R, Stoneking M, Usha Rani MV, Majumder PP. Genetic structure and affinities among tribal populations of southern India: a study of 24 autosomal DNA markers. Ann Hum Genet 2004;68(Pt 2): 128-38.

26 Bird TD, Jarvik GP, Wood NW. Genetic association studies: genes in search of diseases. Neurology 2001;57(7):1153-4.

27 Sander T, Scholz L, Janz D, Epplen JT, Riess O. Length variation of a polyglutamine array in the gene encoding a small-conductance, calciumactivated potassium channel (hKCa3) and susceptibility to idiopathic generalized epilepsy. Epilepsy Res 1999;33(2-3):227-33.

28 Perneger TV. What's wrong with Bonferroni adjustments. BM 1998:316(7139): 1236-8

29 Sun G, Tomita H, Shakkottai VG, Gargus JJ. Genomic organization and promoter analysis of human KCNN3 gene. J Hum Genet 2001:46(8):463-70.

30 Chamberlain NL, Driver ED, Miesfeld RL. The length and location of CAG trinucleotide repeats in the androgen receptor $\mathrm{N}$-terminal domain affect transactivation function. Nucleic Acids Res 1994;22:3181-6.

31 Zhuchenko O, Bailey J, Bonnen P, Ashizawa T, Stockton DW, Amos C Dobyns WB, Subramony SH, Zoghbi HY, Lee CC. Autosomal dominant cerebellar ataxia (SCA6) associated with small polyglutamine expansions in the alpha 1A-voltage-dependent calcium channel. Nat Genet 1997; 15:62-9.

32 Huang $Y$, Paxton WA, Wolinsky SM, Neumann AU, Zhang L, He T, Kang S, Ceradini D, Jin Z, Yazdanbakhsh K, Kunstman K, Erickson D, Dragon E, Landau NR, Phair J, Ho DD, Koup RA. The role of a mutant CCR5 allele in HIV-1 transmission and disease progression. Nat Med 1996:2(11):1240-3.

33 Chaudhuri S, Cariappa A, Tang M, Bell D, Haber DA, Isselbacher KJ, Finkelstein D, Forcione D, Pillai S. Genetic susceptibility to breast cancer: HLA $\mathrm{DQB}^{*} 03032$ and HLA DRB ${ }^{*} 11$ may represent protective alleles. Proc Natl Acad Sci U S A 2000;97(21):11451-4. 